\title{
Impact of Physical Proximity in Romantic Relationships on Trust, Commitment and Relationship Satisfaction among Young Adults
}

\author{
Sanya Taneja ${ }^{1}$, Prerna Goyal ${ }^{2}$ \\ ${ }^{1,2}$ Department of Psychology, Jamia Millia Islamia University, Delhi, India \\ Corresponding author: Sanya Taneja \\ Email-tanejasanya3@gmail.com
}

\begin{abstract}
Background: The present study was aimed at discerning the impact of physical proximity in romantic relationships on trust, commitment and relationship satisfaction among young adults.

Methodology: For the purpose, a sample of 40 young adults was taken. The participants were divided into two groups: (young adults involved in long distance relationship and proximally close relationship) on the basis of their physical proximity. Participants were assessed for their trust, commitment and relationship satisfaction, quantitatively with the help of Trust Scale, Sternberg's Triangular Love Scale and Relationship Assessment scale.

Results: The results of the study indicated that there was a significant difference in the levels of trust and commitment, although an insignificant difference was observed in the levels of relationship satisfaction among couples in long distance and proximally close relationship. And it was observed that, young adults involved in long distance relationship elicited higher levels of commitment with a mean of 115.15 as compared to young adults involved in proximally close relationship with a mean of 98.95; while lower levels of trust was observed among young adults in long distance relationship with a mean of 30.45 as compared to young adults in proximally close relationship with a mean of 38.35 .

Conclusions: There was a significant difference in the levels of trust and commitment, although an insignificant difference was observed in the levels of relationship satisfaction among couples in long distance and proximally close relationship.
\end{abstract}

Keywords: physical proximity, trust, commitment, young adults, relationship satisfaction.

(Paper received $-10^{\text {th }}$ January 2020 , Peer review completed $-27^{\text {th }}$ January 2020)

(Accepted $-28^{\text {th }}$ January 2020)

\section{INTRODUCTION}

Physical proximity: Couples in long-distance relationship often deviates from spatial and socio-temporal norms, that is, social expectations concerning the use of space and time [1]. Often in romantic relationship spatial closeness is assumed however, these preconceived notions are violated for those experiencing long distance relationships [1]. Often couples are defined as "being together," although couples in long-distance relationship negate this definition as they spend at least some of their time apart from each other and in separate spaces [1]. For this study, proximally close dating relationships are defined as couples who are currently dating (not married) and living in the same city while, long distance relationship is defined as couples who are currently dating (not married) and spend much of their time away from their partner in a different city/country.

Trust: Trust is one of the most desired aspects in any close relationship. Love and commitment are mentioned in association with it as a cornerstone of the ideal relationship [2]. Deutsch (1973) has defined 
trust as "confidence that one will find what is desired from another, rather than what is feared." Trust in one's partner involves three stages, which includes predictability, dependability, and faith [3]. Over time people might be confronted with situations in which they must choose between their own interests and that of the relationship. As a result of such situations, individuals and their partners attribute these choices to the development of trust within their relationship [3-5]. Trust is defined as perception of partners' dependability and beliefs regarding the future of the relationship [6]. Rempel and others defined trust as an important concept in human relationship, even more so in close interpersonal relationship (e.g., romantic partners, married couples, etc).

The trust scale is divided into three dimensions: Predictability (emphasizes the consistency and stability of a partner's specific behaviours on the basis of past experience), Dependability (is defined as the dispositional qualities of the significant other, which warrant confidence in the face of risk and potential hurt (e.g., reliability, honesty, etc.) and Faith (is described as feelings of confidence in the relationship and the responsiveness and caring expected from the partner when confronted uncertain future).

Commitment: Sternberg described love in terms of three components. The first component is Intimacy, which was referred to as "feelings of closeness, connectedness, and bondedness in loving relationship. The second component is Passion, which was referred to as "romantic and physical components of a relationship". The third component is Commitment or the decision, which was referred by Sternberg as "in the short-term, to the decision that one loves a certain other, and in the long-term, to maintain that love as one's Commitment". By and large, it refers to one's cognitive preference to be engaged in a relationship and continue that relationship [7]. Decision is the short-term aspect, it refers to one's decision or choice to love someone, whereas Commitment, the long-term aspect refers to one's vow to uphold that love and it slowly increase with time. These components are independent of each other. Commitment is a crucial element in the development and maintains firmness of romantic relationships [3] and affects one's level of evaluating his/her relationship as positive, in happy spirits and being more contended with it [8].

Relationship satisfaction: According to Mattson and others, relationship satisfaction is one of the most important variables in romantic relationship research [9]. Romantic relationship satisfaction corresponds to judgment of an individual about the positivity of his/her relationship [10-11]. Relationship satisfaction is known as the best predictor of stability in the relationship [12]. Many psychologists have described relationship satisfaction differently, like Sternberg defined it as functioning and well-being; Locke and Wallace defined it as 'adjustment; Acitelli and others defined relationship satisfaction as the positive versus negative affect that is experienced in a relationship and is influenced by the extent to which a partner fulfils the individual's most essential needs and it leads to overall well-being [13].

A number of studies has tried to investigate trust, commitment and relationship satisfaction in romantic relationships among young adults. Jenkins and others found that there was no significant difference between the satisfaction levels of people in long distance relationship and geographically proximal relationship [14]. While, some other studies found that participants in long-distance intimate relationships reported higher levels of satisfaction [15]. Also, researchers stated that young adults in long distance relationship reported their relationship as more satisfying than young adults in proximal relationships [16]. Although, some researchers report contradictory lower levels of relationship satisfaction and maintenance among longdistance couples when compared to their proximally close counterparts [17].

Research has compared long dating relationship with proximally close ones and found that the relationship stability, satisfaction, and trust reported by long distance relationship young adults are equal to or better than those reported by proximally close young adults [18]. Guldner and Swensen found that young adults in longdistance and close-proximity relationship had similar levels of commitment [19]. Also, in a study, researchers found no differences in relationship commitment before and after a long-distance separation of freshman young adults [20].

It is possible that couples who experience higher levels of trust also experience higher levels of commitment and possibly higher levels of relationship satisfaction. Within long-distance dating relationship, commitment is likely not sufficient if the partners do not trust each other [21]. Some researchers [21-22] indicate that for this reason, long-distance couples tend to idealize each other as well as the relationship, particularly when reality may present a threat of distrust in the relationship. 


\section{METHODOLOGY}

\section{Participants}

A sample of 40 young adults belonging to the age group of 18-25 years was taken. The sample was further divided into two groups having 20 participants each on the basis of their physical proximity respectively.

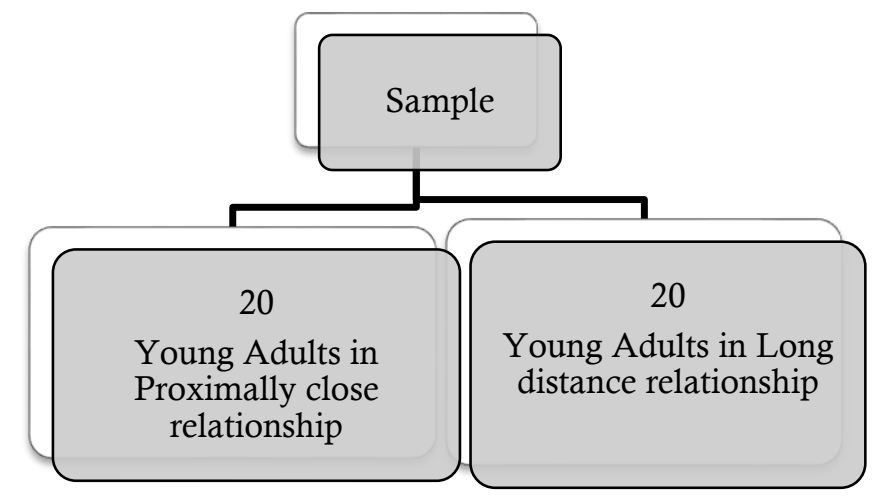

\section{Instruments}

The following three quantitative tools were used -

1. Trust Scale: The Trust Scale by Rempel and others was used to assess the levels of trust in participants. This version had dependability, faith and predictability sub-scales with a total of 17 items. The participants were supposed to respond using a 7-point likert type scale. An example of an item on the trust scale is "I can rely on my partner to react in a positive way when I expose my weaknesses to him/her." The overall cronbach alpha was 0.81 and the subscale reliabilities were found 0.80 for faith, 0.72 for dependability and 0.70 for predictability subscale. The three subscales were found to be moderately inter-correlated (range of 0.27-0.46). [23].

2. Triangular Love Scale: The Triangular Love Scale by Sternberg was used to assess participants levels of commitment [24]. This version had intimacy, passion and commitment sub-scales with a total of 45 items, broken down into 15 item subscales. The participants were supposed to respond using a nine-point likert type scale ranging from 1 indicating not at all applicable to 9 indicating strongly applicable. The participants were given instructions to score each statement depending on the degree to which they either could relate with the statements presented. An example of an item on the commitment subscale is: "I view my relationship with (the person I love or care for deeply) as permanent". The overall coefficient alpha was 0.97 , while the coefficient alpha for commitment was 0.94 . The inter-scale correlations between the subscales were also found to be satisfactory.

3. Relationship Assessment Scale: Relationship Assessment Scale (RAS) given by Hendrick is used to determine the participant's level of satisfaction with their romantic partners. It is a self-reported measure, that consists of 7 items with 5-point Likert scale $(1=$ Low, $5=$ High) (e.g., "How well does your partner meet your needs?") [25]. The Relationship Assessment Scale has illustrated reliability with an alpha of 0.86 , a mean inter-item correlation of 0.49 , and a test-retest reliability of 0.85. Empirical testing of psychometric properties revealed the maintenance of high internal consistency, reliability, convergent validity, and predictive validity across a diversity of relationship types (i.e., romantic partners, parents, friends, and other family members) [26].

\section{STATISTICAL ANALYSIS}

Data collected was scored and descriptive statistics were used to calculate the mean scores and standard deviation scores, along with t-test on the basis of physical proximity among young adults on the Trust Scale, Sternberg's Triangular Love Scale (Commitment sub-scale) and Relationship Assessment scale. 


\section{RESULTS AND DISCUSSION}

Table 1 - Scores on various scales in the sample

\begin{tabular}{|c|c|c|c|c|c|}
\hline & $\begin{array}{l}\text { Relationship } \\
\text { status }\end{array}$ & $\mathbf{N}$ & Mean & t value & Significance \\
\hline \multirow[t]{2}{*}{ Trust } & Proximally close & 20 & 38.35 & \multirow[b]{2}{*}{5.014} & \multirow[b]{2}{*}{$0.0001^{*}$} \\
\hline & $\begin{array}{l}\text { Long-distance } \\
\text { relationship }\end{array}$ & 20 & 30.45 & & \\
\hline \multirow[t]{2}{*}{ Commitment } & Proximally close & 20 & 98.95 & \multirow{2}{*}{4.238} & \\
\hline & $\begin{array}{l}\text { Long-distance } \\
\text { relationship }\end{array}$ & 20 & 115.15 & & $0.0001^{*}$ \\
\hline \multirow{2}{*}{$\begin{array}{l}\text { Relationship } \\
\text { Satisfaction }\end{array}$} & Proximally close & 20 & 25.55 & \multirow[b]{2}{*}{0.225} & \multirow[t]{2}{*}{$0.823 \mathrm{NS}$} \\
\hline & $\begin{array}{l}\text { Long-distance } \\
\text { relationship }\end{array}$ & 20 & 25.30 & & \\
\hline
\end{tabular}

The present study was aimed at discerning the impact of physical proximity in romantic relationships on trust, commitment and relationship satisfaction among young adults. For the purpose, a sample of 40 young adults was taken. The participants were divided into two groups: (young adults involved in long distance and proximally close relationship) on the basis of their physical proximity.

Trust is defined as perception of partners' dependability and beliefs regarding the future of the relationship [6]. Rempel defined trust as an important concept in human relationships, even more so in close interpersonal relationship (e.g., romantic partners, married couples, etc). The trust scale is divided into three dimensions: Predictability (emphasizes the consistency and stability of a partner's specific behaviors on the basis of past experience), Dependability (is defined as the dispositional qualities of the significant other, which warrant confidence in the face of risk and potential hurt (e.g., reliability, honesty, etc.) and Faith (is described as feelings of confidence in the relationship and the responsiveness and caring expected from the partner when confronted uncertain future).

Looking at Table 1 , it is indicated that there is a significant difference in the levels of trust among young adults involved in proximally close and long-distance relationships $\left(t_{(38,1)}=5.014, p<0.01\right)$ and it is also observed that, young adults in proximally close relationships elicit higher levels of trust with the mean of 38.35 as compared to young adults in long-distance relationships with the mean of 30.45 . The effect size is calculated with the help of Cohen's $d$ formula and it came out to be $d=1.58$, since the value of the effect size of Cohen's $d$ is higher than 0.7 , this is indicative of a high effect size, which in turn indicates that there is high practicality value of the given data.

As Stafford has compared long dating relationships with proximally close ones and found that the relationship stability, satisfaction, and trust reported by long distance relationship young adults are equal to or better than those reported by proximally close young adults [27]. Thus, the present study is parallel to the findings of Stafford's study and it indicates that there is a high impact of physical proximity on the levels of trust among young adults involved in romantic relationship [10]. Sternberg described love in terms of three components: Intimacy, Passion, and Commitment. Commitment or the decision is referred by Sternberg as in the short-term, to the decision that one loves a certain other, and in the long-term, to maintain that love as one's Commitment [7].

Looking at Table 1, the scores of commitment, it is indicated that there is a significant difference in the levels of commitment among young adults involved in proximally close and long-distance relationships $(\mathrm{t}(38,1)=$ $4.238, \mathrm{p}<0.01)$ and it is observed that, young adults involved in long-distance relationships elicit higher levels of commitment with the mean of 115.15 as compared to young adults involved in proximally close relationships with the mean of 98.95. The effect size is calculated with the help of Cohen's $d$ formula and it 
came out to be $d=1.34$, since the value of the effect size of Cohen's $d$ is higher than 0.7 , this is indicative of a high effect size, which in turn indicates that there is high practicality value of the given data.

As Guldner and Swensen found that young adults in long-distance and close-proximity relationship had similar levels of commitment. Also, in a study by Baxter and Bullis, they found no differences in relationship commitment before and after a long-distance separation of young adults. Thus, the present study is contradictory to the findings of the two studies mentioned, as it indicates that there are higher levels of commitment among young adults in long-distance relationship as compared to young adults in proximally close relationships, which is indicative of a high impact of physical proximity on commitment among young adults involved in romantic relationships [19-20].

Hendrick in the Relationship Assessment Scale propounds to measure relationship satisfaction in generic terms [25]. Looking at Table 1, it is indicated that there is no significant difference in the levels of relationship satisfaction among young adults involved in proximally close and long-distance relationships $\left(\mathrm{t}_{(38,1)}=.225\right.$, $\mathrm{p}>0.05$ ). As researchers found that there was no significant difference between the satisfaction levels of young adults in long distance relationship and geographically proximal relationship. While, some other studies [14-17] found that participants in long-distance intimate relationship reported higher levels of satisfaction.

\section{CONCLUSION}

Thus, from the present study it can be concluded that there was a significant difference in the levels of trust and commitment, although an insignificant difference was observed in the levels of relationship satisfaction among couples in long distance and proximally close relationship. And it was observed that, young adults in long distance relationship elicited higher levels of commitment with a mean of 115.15 as compared to young adults involved in proximally close relationship with a mean of 98.95; while lower levels of trust was observed among young adults in long distance relationship with a mean of 30.45 as compared to young adults in proximally close relationship with a mean of 38.35. But, in order for the results to be generalized to the larger population we need to take into consideration a larger sample size. Also, it would be interesting to study the gender differences pertaining to the impact of physical proximity on the dimensions of trust, commitment and relationship satisfaction.

\section{REFERENCES}

1. Kolozsvari O. Physically We Are Apart, Mentally We Are Not. Creating a Shared Space and a Sense of Belonging in Long-Distance Relationships. Qual Sociol Rev 2015;11(4);102-15.

2. Hendrick SS, Dicke A, Hendrick C. The relationship assessment scale. J Soc Personal Relat 1998;15(1):13742.

3. Adams JM, Jones WH, editors. Handbook of interpersonal commitment and relationship stability. Springer Science \& Business Media; 1999.

4. Van Lange PA, Rusbult CE, Drigotas SM, Arriaga XB, Witcher BS, Cox CL. Willingness to sacrifice in close relationships. J Personal Soc Psychol 1997;72(6):1373-8.

5. Stanley SM, Markman HJ, Whitton SW. Communication, conflict, and commitment: Insights on the foundations of relationship success from a national survey. Fam Process 2002;41(4):659-75.

6. Rempel JK, Holmes JG, Zanna MP. Trust in close relationships. J Personal Soc Psychol 1985;49(1):95-101.

7. Sternberg RJ. A triangular theory of love. Psychol Rev 1986;93(2):119-28.

8. Acker $\mathrm{M}$, Davis $\mathrm{MH}$. Intimacy, passion and commitment in adult romantic relationships: A test of the triangular theory of love. J Soc Personal Relat 1992;9(1):21-50.

9. Mattson RE, Rogge RD, Johnson MD, Davidson EK, Fincham FD. The positive and negative semantic dimensions of relationship satisfaction. Personal Relat 2013;20(2):328-55.

10. Arriaga XB. The ups and downs of dating: Fluctuations in satisfaction in newly formed romantic relationships. J Personal Soc Psychol 2001;80(5):754-9.

11. Avivi YE, Laurenceau JP, Carver CS. Linking relationship quality to perceived mutuality of relationship goals and perceived goal progress. J Soc Clin Psychol 2009;28(2):137-64.

12. Horn KR, Arnone A, Nesbitt K, Desletts L, Sears T, Giffin M, Brudi R. Physical distance and interpersonal characteristics in college students' romantic relationships. Personal Relat 1997;4(1):25-34. 
13. Baumeister RF, Leary MR. The need to belong: desire for interpersonal attachments as a fundamental human motivation. Psychol Bull 1995;117(3):497-503.

14. Dellmann-Jenkins M, Bernard-Paolucci TS, Rushing B. Does distance make the heart grow fonder? A comparison of college students in long-distance and geographically close dating relationships. Coll Stud J 1994;28:212-8.

15. Kelmer G, Rhoades GK, Stanley S, Markman HJ. Relationship quality, commitment, and stability in longdistance relationships. Fam Process 2013;52(2):257-70.

16. Stafford L, Reske JR. Idealization and communication in long-distance premarital relationships. Fam Relat 1990;1:274-9.

17. Le B, Agnew CR. Need fulfilment and emotional experience in interdependent romantic relationships. J Soc Pers Relat 2001;18(3):423-40.

18. Stafford L. Geographic distance and communication during courtship. Commun Res 2010;37(2):275-97.

19. Guldner GT, Swensen CH. Time spent together and relationship quality: Long-distance relationships as a test case. J Soc Pers Relat 1995;12(2):313-20.

20. Baxter LA, Bullis C. Turning points in developing romantic relationships. Hum Commun Res 1986;12(4):46993.

21. Ladd PD. Relationships and patterns of conflict resolution: A reference book for couples counseling. University Press of America; 2007.

22. Stafford L, Reske JR. Idealization and communication in long-distance premarital relationships. Fam Relat 1990;1:274-9.

23. Rempel JK, Holmes JG, Zanna MP. Trust in close relationships. J Personal Soc Psychol 1985;49(1):95-101.

24. Sternberg RJ. Construct validation of a triangular love scale. Eur J Soc Psychol 1997;27(3):313-35.

25. Hendrick SS. A generic measure of relationship satisfaction. J Marriage Fam 1988;1:93-8.

26. Renshaw KD, Blais RK, Caska CM. Distinctions between hostile and nonhostile forms of perceived criticism from others. Behav Ther 2010;41(3):364-74.

$* * * * * * * * * * * * * * * * * * * * * * * * * * * * * * * * * * * *$

Acknowledgements - Nil

Conflict of Interest - Nil

Funding - Nil 